\title{
Ciprofloxacin reduces tenocyte viability and proteoglycan synthesis in short-term explant cultures of equine tendon
}

\author{
Stuart James ${ }^{\text {Corresp., } 1}$, Johannes Schuijers ${ }^{1}$, John Daffy ${ }^{2}$, Jill Cook $^{3}$, Tom Samiric ${ }^{\text {Corresp. } 1}$ \\ ${ }^{1}$ Department of Physiology, Anatomy, and Microbiology, La Trobe University, Melbourne, Victoria, Australia \\ 2 Department of infectious Diseases, St. Vincent's Hospital, Melbourne, Victoria, Australia \\ 3 Sports and Exercise Medicine Research Centre, La Trobe University, Melbourne, Victoria, Australia \\ Corresponding Authors: Stuart James, Tom Samiric \\ Email address: stuart.james@latrobe.edu.au, t.samiric@latrobe.edu.au
}

Fluoroquinolones are an effective, broad-spectrum antibiotic used to treat an array of bacterial infections. However, they are associated with an increased risk of tendinopathy and tendon rupture even after discontinuation of treatment. This condition is known as fluoroquinolone-associated tendinopathy, the underlying mechanisms of which are poorly understood. While many factors may be involved in the pathophysiology of tendinopathies in general, changes in tenocyte metabolism and viability, as well as alteration of proteoglycan metabolism are prominent findings in the scientific literature. This study investigated the effects of ciprofloxacin, a common fluoroquinolone, on cell viability, proteoglycan synthesis, and proteoglycan mRNA expression in equine superficial digital flexor tendon explants after 96 hours treatment with between $1-300 \mu \mathrm{g} / \mathrm{mL}$ ciprofloxacin, and again after 8 days discontinuation of treatment. Ciprofloxacin caused significant reductions in cell viability by between $25-33 \%$ at all dosages except $10 \mu \mathrm{g} / \mathrm{mL}$, and viability decreased further after 8 days discontinuation of treament. Proteoglycan synthesis significantly decreased by approximately $50 \%$ in explants treated with $100 \mu \mathrm{g} / \mathrm{mL}$ and $300 \mu \mathrm{g} / \mathrm{mL}$, however this effect reversed after 8 days in the absence of treatment. No significant $m$ RNA expression changes were observed after the treatment period with the exception of versican which was down-regulated at the highest concentration of ciprofloxacin. After the recovery period, aggrecan, biglycan and versican genes were all significantly downregulated in explants initially treated with 1$100 \mu \mathrm{g} / \mathrm{mL}$. Results from this study corroborate previously reported findings of reduced cell viability and proteoglycan synthesis in a whole tissue explant model and provide further insight into the mechanisms underlying fluoroquinolone-associated tendinopathy and rupture. This study further demonstrates that certain ciprofloxacin induced cellular changes are not rapidly reversed upon cessation of treatment which is a novel finding in the literature. 


\section{CIPROFLOXACIN REDUCES TENOCYTE VIABILITY}

2 PROTEOGLYCAN SYNTHESIS IN SHORT-TERM

3 EXPLANT CULTURES OF EQUINE TENDON

4

5

6

7

8

9

10

11

12

13

14

15

James $\mathrm{S}^{1}$, Schuijers $\mathrm{J}^{1}$, Daffy $\mathrm{J}^{2}$, Cook $\mathrm{J}^{3}$, Samiric $\mathrm{T}^{1}$

${ }^{1}$ Department of Physiology, Anatomy, and Microbiology, La Trobe University, Melbourne, Victoria, Australia.

${ }^{2}$ Department of Infectious Diseases, St Vincent's Hospital, Melbourne, Australia.

${ }^{3}$ Sports and Exercise Medicine Research Centre, La Trobe University, Melbourne, Victoria, Australia

Corresponding Author:

Dr T. Samiric

School of Life Sciences

La Trobe University

Melbourne, Australia, 3086

Email address: T.Samiric@latrobe.edu.au 


\section{Abstract}

23 Fluoroquinolones are an effective, broad-spectrum antibiotic used to treat an array of bacterial

24 infections. However, they are associated with an increased risk of tendinopathy and tendon

25 rupture even after discontinuation of treatment. This condition is known as fluoroquinolone-

26 associated tendinopathy, the underlying mechanisms of which are poorly understood. While

27 many factors may be involved in the pathophysiology of tendinopathies in general, changes in

28 tenocyte metabolism and viability, as well as alteration of proteoglycan metabolism are

29 prominent findings in the scientific literature. This study investigated the effects of ciprofloxacin,

30 a common fluoroquinolone, on cell viability, proteoglycan synthesis, and proteoglycan $m$ RNA

31 expression in equine superficial digital flexor tendon explants after 96 hours treatment with

32 between 1 - $300 \mu \mathrm{g} / \mathrm{mL}$ ciprofloxacin, and again after 8 days discontinuation of treatment.

33 Ciprofloxacin caused significant reductions in cell viability by between $25-33 \%$ at all dosages

34 except $10 \mu \mathrm{g} / \mathrm{mL}$, and viability decreased further after 8 days discontinuation of treatment.

35 Proteoglycan synthesis significantly decreased by approximately $50 \%$ in explants treated with

$36100 \mu \mathrm{g} / \mathrm{mL}$ and $300 \mu \mathrm{g} / \mathrm{mL}$, however this effect reversed after 8 days in the absence of treatment.

37 No significant $m$ RNA expression changes were observed after the treatment period with the

38 exception of versican which was down-regulated at the highest concentration of ciprofloxacin.

39 After the recovery period, aggrecan, biglycan and versican genes were all significantly

40 downregulated in explants initially treated with $1-100 \mu \mathrm{g} / \mathrm{mL}$. Results from this study

41 corroborate previously reported findings of reduced cell viability and proteoglycan synthesis in a

42 whole tissue explant model and provide further insight into the mechanisms underlying

43 fluoroquinolone-associated tendinopathy and rupture. This study further demonstrates that

44 certain ciprofloxacin induced cellular changes are not rapidly reversed upon cessation of

45 treatment which is a novel finding in the literature. 
46

47 Introduction

48 Fluoroquinolones (FQs) are a group of broad-spectrum antibiotics which have been used for

49 several decades to treat a variety of bacterial infections. While considered relatively safe, there is

50 growing literature indicating an association of FQ use and tendon pathology, particularly of the

51 Achilles tendon (Ribard et al. 1992). Although the reported incidence of FQ-induced

52 tendinopathy is low among the general population ( $<1 \%$ of patient prescriptions) (Gillet et al.

53 1995; Harrell 1999; Wilton et al. 1996), in 2008 the US Food and Drug Administration included

54 a black box warning label on almost all prescribed FQs.

55

56 FQ treatment has been shown to increase the risk of Achilles tendinopathy $~ 4$-fold and tendon

57 rupture $\sim 2.5$-fold; this risk is further increased with concurrent corticosteroid therapy (Alves et

58 al. 2019) and with aging (tendon rupture being $\sim 3 x$ higher for individuals over 60 years of age

59 (Corrao et al. 2006). Researchers have reported that pathology could be present as early as 2

60 hours after initial treatment to as late as 6 months after stopping treatment (Corrao et al. 2006;

61 Fernandez-Cuadros et al. 2019; Lewis \& Cook 2014).

62

63 The specific mechanism responsible for FQ-induced tendinopathy remains unclear. Previous

64 studies have suggested that the tendon cells (tenocytes) are the primary site of FQ toxicity,

65 including inhibition of tenocyte proliferation and migration (Burkhardt et al. 1990; Williams et

66 al. 2000), reduced mitochondrial activity (Bernard-Beaubois et al. 1998), changes in expression

67 of inflammatory mediators, and reduced collagen and proteoglycan synthesis (Bernard-Beaubois

68 et al. 1998; Williams et al. 2000). Other authors have shown that FQs interfere directly with the

69 extracellular matrix proteins (Bendele et al. 1990).

Peer] reviewing PDF | (2021:02:58014:1:0:NEW 20 Jun 2021) 
71 Tenocytes are modified fibroblasts which are responsible for the synthesis, maintenance, and

72 degradation of the extracellular matrix. This matrix is comprised predominantly of parallel-

73 arranged Type I collagen fibres with proteoglycans and other non-collagenous proteins

74 interspersed. Although proteoglycans make up $<3 \%$ of the tendon matrix, these macromolecules 75 contribute significantly to the structural integrity of the tissue.

76

77 Proteoglycans are a heavily glycosylated protein consisting of a core protein with one or more 78 sulphated glycosaminoglycan (sGAG) chains covalently attached. The sGAGs typically act to 79 sequester cations and subsequently water, providing hydration, stability, and pressure to the 80 tissue to improve compressive strength. We have previously shown that the small leucine-rich 81 proteoglycans, decorin and biglycan, make up approximately $80 \%$ of total proteoglycans in 82 energy-storage tendons such as the Achilles (Samiric et al. 2004). These are predominantly 83 involved in regulating collagen fibrillogenesis; in their absence, collagen fibrils are coarse, 84 irregular and disorganized (Danielson et al. 1997). The large aggregating proteoglycans, 85 aggrecan and versican, make up the remainder and due to their abundance of sGAGs, provide the 86 tissue with a high capacity to resist compressive forces associated with loading and mobilisation. 87 Increased levels of aggrecan have been associated with tendon pathology, causing increased 88 hydration and swelling of the tissue (Riley 2008).

89

90 The aim of this study was to utilise an explant culture system using tendons derived from equine 91 superficial digital flexor tendon (SDFT) to examine the effects of ciprofloxacin (CPX) on tendon 
92 proteoglycan synthesis. This study further aimed to determine whether changes in tenocyte

93 viability or proteoglycan synthesis are associated with discontinuation of the antibiotic.

94

95

96

97

98

99

100

101

102

103

104

105

106

107

108

109

110

111

112

113

114

115

\section{Materials \& Methods}

97

\section{Materials Used}

Ciprofloxacin lactate solution $(100 \mathrm{mg} / 50 \mathrm{~mL})$ was obtained from Sandoz (NSW, Australia) for use in tissue explant culture. Dulbecco's Modified Eagle's Medium (DMEM), penicillinstreptomycin, newborn calf serum (NBCS) and PrestoBlue ${ }^{\circledR}$ Reagent were purchased from Life Technologies (NY, USA). Sulfur-35 radionuclide and ScintiSafe 30\% was purchased from PerkinElmer (Boston, USA). PD-10 (Sephadex G-25) columns were obtained from GE Life Sciences (Uppsala, Sweden). Papain and Sepharose CL-4B resin were purchased from SigmaAldrich (St. Louis, USA). RNAlater was from Qiagen (Hilden, Germany). PureZOL reagent, Fatty and fibrous tissue RNA isolation kits (Cat\#732-6820), RNA-cDNA reverse transcription kits (Cat\#170-8890), and an iCycler IQ detection system were purchased from Bio-Rad (Hercules, USA). Bertin Precellys 24 homogeniser and CK 28 ceramic homogeniser beads were purchased from Bertin Technologies (France). NanoDrop 2000 was bought from Thermo Fisher Scientific (Waltham, USA). Premier Biosoft (Palo Alto, USA) developed beacon primer design software. GraphPad (La Jolla, California) provided prism 5.0 data analysis software.

\section{Tissue Explant Culture}

The mid-carpal segments $(\sim 5 \mathrm{~cm})$ of the superficial digital flexor tendon (SDFT) were harvested under aseptic conditions from the forelimbs of Thoroughbred horses euthanized for reasons 
116 unrelated to tendon disease. Specimens from up to eight individual adult equine ( $\sim$ yrs) were

117 obtained from a local knackery.

118

119 The paratenon was removed and the remaining samples of core tendon were cut into small pieces

120 weighing $\sim 100 \mathrm{mg}$ each. These were incubated for $24 \mathrm{hrs}$ at $37^{\circ} \mathrm{C}$ in low glucose DMEM $(10 \mathrm{~mL}$

121 per $1 \mathrm{~g}$ tissue) supplemented with $10 \%(\mathrm{v} / \mathrm{v})$ NBCS and $1 \%(\mathrm{v} / \mathrm{v})$ penicillin/streptomycin.

122 Duplicate samples of approximately $100 \pm 20 \mathrm{mg}$ tissue were then distributed between treatment

123 groups and placed into individual sterile screw-capped vials containing the same DMEM

124 supplemented with 10\% NBCS, as described above, alone (control) or containing ciprofloxacin 125 (treatment).

Ciprofloxacin Treatment

128 CPX-treated and control (CT) tissue explants were cultured in DMEM with 10\% NBCS for

129 96hrs using duplicate cultures for each sample. CPX was added to the culture medium of

130 experimental groups at four different doses: 1, 10, 100 and $300 \mu \mathrm{g} / \mathrm{mL}$. The lower range of

131 concentrations was selected to include dosages that reflect serum CPX concentrations reported

132 clinically, and higher dosages are consistent with similar in vitro toxicological studies. CT

133 samples were those in DMEM alone. The culture medium was changed after $48 \mathrm{hrs}$.

134 In parallel experiments investigating whether discontinuation of CPX affects tendon metabolism,

135 at the end of the $96 \mathrm{hr}$ CPX treatment period, samples were thoroughly washed using sterile PBS

136 and placed in DMEM alone. These samples were incubated for a further 8 days under control

137 conditions, with media replenished every $48 \mathrm{hrs}$. 


\section{PrestoBlue $^{\circledR}$ Reagent Assay}

140 The effect of CPX on total cell viability in explant cultures of equine tendon after 96hrs of

141 treatment and subsequent 8-day recovery period was measured by quantification using a

142 PrestoBlue ${ }^{\circledR}$ reagent assay. The tendon explants were incubated with DMEM containing 10\%

$143(\mathrm{v} / \mathrm{v})$ PrestoBlue ${ }^{\circledR}$ reagent for $3 \mathrm{hrs}$ at $37^{\circ} \mathrm{C}$. Following this, $200 \mu \mathrm{L}$ reaction mixtures were

144 transferred to 96-well plates for measurement of fluorescence (Triad MX multimeter reader) with

145 an excitation wavelength of 530nm and an emission wavelength of 590nm. DMEM with 10\%

146 PrestoBlue ${ }^{\circledR}$ reagent, without any tendon explant, was used as a reagent blank for the

147 fluorometric measurements. The tendon explants were rinsed thoroughly in sterile PBS to

148 remove any residual PrestoBlue ${ }^{\circledR}$ reagent after each assay.

\section{Determination of sulphated glycosaminoglycan concentration}

151 A dimethylmethylene blue (DMB) spectrophotometric assay (Farndale et al. 1986) was used to 152 quantify the level of sulphated glycosaminoglycans (sGAG) in papain-digested tendon samples.

153 Approximately 10mg wet weight tissue was lyophilised to determine tissue dry weight and then 154 digested with $125 \mu \mathrm{g} / \mathrm{mL}$ papain, $10 \mathrm{mM}$ cysteine hydrochloride, $2 \mathrm{mM}$ EDTA and $0.1 \mathrm{M}$ 155 phosphate buffer (0.2M monosodium dihydrogen orthophosphate and 0.2M disodium hydrogen 156 orthophosphate; $\mathrm{pH} 7.0$ ) for $18 \mathrm{hrs}$ at $65^{\circ} \mathrm{C}$. Triplicate aliquots of the papain-digested tendon 157 samples were immediately analysed at an absorbance 525nm (Farndale et al. 1986). The assay 158 was calibrated by use of standards containing up to $40 \mu \mathrm{g} / \mathrm{mL}$ bovine chondroitin sulphate. The 159 sGAG concentration in the tendon samples was obtained by comparison with the standard curve 160 and expressed as $\mu \mathrm{g}$ of chondroitin sulphate per mg dry weight of tissue. 
162

163

164

165

166

167

168

169

170

171

172

173

174

175

176

177

178

179

180

181

182

183

184

\section{Determination of newly synthesised ${ }^{35}$ S-labelled proteoglycans}

The amount of newly synthesised proteoglycans by tendon explants was measured by ${ }^{35} \mathrm{~S}-$ sulphate labelling. At the end of the culture periods, tissue samples were washed thoroughly in sulphate-free medium and then placed in sulphate-free medium containing $150 \mu \mathrm{Ci} / \mathrm{mL}{ }^{35} \mathrm{~S}$ sulphate at $37^{\circ} \mathrm{C}$ for $6 \mathrm{hrs}$. A single batch of medium containing ${ }^{35} \mathrm{~S}$-sulphate was used for all incubations. At the end of the incubation period, ${ }^{35} \mathrm{~S}$-labelled proteoglycans were extracted with 4M Guanidine Hydrochloride $(\mathrm{GnHCl} ; \mathrm{pH} 6.1)$ in the presence of a proteinase inhibitor cocktail at $4^{\circ} \mathrm{C}$ for $72 \mathrm{hrs}$, followed by $0.5 \mathrm{M} \mathrm{NaOH}$ at room temperature for $24 \mathrm{hrs}$.

Aliquots $(0.5 \mathrm{~mL})$ of the tissue extracts were applied to PD-10 (Sephadex G-25) columns, equilibrated and eluted with $4 \mathrm{M} \mathrm{GnHCl,} 0.1 \mathrm{M}$ sodium sulphate, $0.05 \mathrm{M}$ sodium acetate, $0.1 \%$ (v/v) Triton X-100; pH 6.1. Aliquots of the eluted samples were then collected in vials containing a scintillant cocktail (ScintiSafe 30\%), and the radioactivity in each sample assessed with a Packard 1500 TRI-CARB liquid scintillation counter.

\section{RNA Extraction and Reverse Transcriptase}

At the end of the culture period tissue samples $(\sim 50-100 \mathrm{mg}$ wet weight $)$ were placed in RNAlater ${ }^{\mathrm{TM}}$ at $4^{\circ} \mathrm{C}$ overnight, and then stored at $-80^{\circ} \mathrm{C}$ for future analysis. Tissue was homogenised in PureZOL reagent using a Bertin Precellys 24 homogeniser with the aid of ceramic beads (CK 28) and a program consisting of 6,000g for 20sec. This was repeated five times until all visible tissue was dissolved. Following homogenisation, total RNA was isolated using a kit according to the recommendations of the manufacturer. The procedure included digestion of genomic DNA with DNase I. RNA integrity and concentration were determined using a Nanodrop 2000. Complementary DNA (cDNA) was synthesised using a reverse 
185 transcription kit. The resulting cDNA was subjected to real-time PCR amplification in an iCycler 186 iQ Detection System (Bio-Rad, Hercules, USA). Equine oligonucleotide sequences of the 187 specific primers used in this study were designed using Beacon Designer and are shown in Table 1881. 189

190 Quantification of Gene Expression

191 The values obtained for $m$ RNA expression for the genes of interest were normalised for GAPDH 192 housekeeping gene in the same sample. This was calculated according to relative quantification 193 method using the $\Delta \Delta \mathrm{Ct}$ method where $\mathrm{Ct}$ is the cycle number of the detection threshold, and $194 \Delta \Delta \mathrm{Ct}$ shows the difference in threshold cycle $(\Delta \mathrm{Ct})$ between gene of interest and GAPDH.

\section{Data Analysis}

197 Results are represented as mean \pm standard error of the mean (SEM). Experiments were repeated 198 on separate occasions using tendon tissue derived from a different horse each time. Each datum from an individual experiment is compared to a CT sample from the same animal. Overall experiment data are presented as a mean of all tissue samples compared to their respective control after $96 \mathrm{hr}$ treatment or $96 \mathrm{hr}$ treatment followed by 8 days in CT conditions (recovery).

All statistical tests were performed using Prism 9.0 software. Repeated measures one-way 203 analysis of variance (ANOVA) with Greenhouse-Geisser correction followed by post-hoc Dunnett's-test was used to determine multiplicity adjusted significance between each treatment condition and control. Differences were considered statistically significant at $p<0.05$.

\section{Results}


210 Tendon explant cultures established from SDFTs from 6-yr old horses were exposed to 1-

$211300 \mu \mathrm{g} / \mathrm{mL}$ CPX for $96 \mathrm{hrs}$. The PrestoBlue ${ }^{\circledR}$ viability assay revealed that 1,100 and $300 \mu \mathrm{g} / \mathrm{mL}$

212 CPX reduced cell viability by approx. $25 \%(p=0.02), 33 \%(p=0.003)$, and $32 \%(p=0.004)$

213 compared to CT, respectively (Figure 1). Although, a downward trend was observed in samples

214 exposed to $10 \mu \mathrm{g} / \mathrm{mL} \mathrm{CPX}$, this was not shown to be significant $(p>0.05) .8$ days after

215 discontinuation of treatment, tenocyte viability was reduced in a dose dependent manner (Figure 216 2) by approx. $30 \%(p=0.048), 34 \%(p=0.043), 36 \%(p=0.02)$, and $51 \%(p=0.0036)$ compared to 217 CT in samples initally treated with $1,10,100, \& 300 \mu \mathrm{g} / \mathrm{mL} \mathrm{CPX}$, respectively.

218

219 Effects on sulphated glycosaminoglycan levels (sGAG)

220 The sGAG levels present in the tissue following treatment with $1-300 \mu \mathrm{g} / \mathrm{mL}$ CPX for $96 \mathrm{hrs}$ was 221 determined by a DMB spectrophotometric assay. There was no significant change in sGAG 222 levels in CPX-treated tendon explants compared with CT ( $p>0.05$; Figure 3).

223

224

Effects on Newly Synthesised ${ }^{35}$ S-labelled Proteoglycan Concentrations

225 The rate of incorporation of radiolabeled sulphate into newly synthesised PGs following 226 treatment with $\mathrm{CPX}$ is shown in Figure 4. The amount of ${ }^{35} \mathrm{~S}$-sulphate incorporation into PGs 227 was reduced by approx. $48 \%(p=0.0037)$ and $51 \%(p=0.0002)$ in explant cultures treated with 228100 and $300 \mu \mathrm{g} / \mathrm{mL}$ CPX, respectively. ${ }^{35} \mathrm{~S}$-sulphate incorporation into PGs in samples treated 229 with 1,100 , and $300 \mu \mathrm{g} / \mathrm{mL}$ was at $101 \%, 115 \%$, and $85 \%$ of CT levels 8 days after 230 discontinuation of CPX, respectively $(p>0.05) .{ }^{35}$ S-sulphate incorporation into PGs was 
231 increased by $40 \%$ in samples treated with $10 \mu \mathrm{g} / \mathrm{mL}$ CPX after the recovery period $(p=0.0147$;

232 Figure 5).

233

234 Effects on mRNA expression of Proteoglycan Genes

235 We analysed several PG genes including decorin, fibromodulin, biglycan, aggrecan and versican 236 in CPX-treated and untreated explants (Figures 6 - 10). The only significant change in $m$ RNA 237 expression of any PG gene observed after 96hrs treatment with CPX was a 0.49-fold down238 regulation of versican at $300 \mu \mathrm{g} / \mathrm{mL}(p=0.001$; Figure 10). 8 days after discontinuation of CPX 239 treatment, no significant differences were observed in $m$ RNA expression of decorin or 240 fibromodulin (Figures 11 \& 12). However, biglycan $m$ RNA was down-regulated to 0.64-fold $241(p=0.001)$, and 0.67 -fold $(p=0.0095)$ of CT in explants originally treated with 10 , and $100 \mu \mathrm{g} / \mathrm{mL}$ 242 CPX (Figure 13). Aggrecan was down-regulated to 0.56-fold $(p=0.007)$ and 0.45 -fold $(p=0.01)$

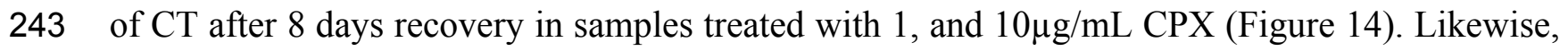
244 versican $m$ RNA was down-regulated after 8 days discontinuation of treatment by 0.5 -fold $245(p=0.0032)$ compared to CT in explants initially treated with $1 \mu \mathrm{g} / \mathrm{mL} \mathrm{CPX} \mathrm{(Figure} \mathrm{15).}$

246

247

248 Discussion

249 Changes in tendon metabolism following FQ treatment in a cell culture system are well 250 251 252 253 viability but also reduces newly synthesised PGs in equine tendon explant cultures. 
255 To provide a basis for extrapolating these results to clinical practice, we considered the 256 pharmacokinetic properties of FQs in our study (Stahlmann et al. 1995; Zhanel \& Noreddin 2001;

257 Zhanel et al. 2001). The lowest range of concentrations tested $(1-10 \mu \mathrm{g} / \mathrm{mL})$ reflect plasma 258 concentrations seen in humans treated with CPX. Our highest concentrations used in this study $259(100-300 \mu \mathrm{g} / \mathrm{mL})$ are common in such in vitro FQ toxicological studies and are consistent with 260 highest concentrations used by other investigators (Egerbacher et al. 2001; Lim et al. 2008; Yoon 261 et al. 2004a; Yoon et al. 2004b). Despite apparent articular tissue accumulation of FQs, with 262 concentrations as high as approximately $30 \mu \mathrm{g} / \mathrm{mL}$ reported in articular cartilage in canines 263 treated with ofloxacin (Yoshida et al. 1998), such concentrations have not been demonstrated to 264 occur in tendon tissue in vivo and peak concentration of CPX achieved in tendon is unknown 265 (Lewis \& Cook 2014). As such, the effects observed in this study at higher dosages may have 266 limited applicability to clinical settings.

267

268 The mechanism by which CPX suppressed tenocyte viability is unknown, however other 269 investigators have shown that it may be due to a number of factors including altered metabolism 270 of signalling molecules, such as down-regulation of cytokines involved in G2/M cell cycle arrest 271 and an increase in FAK phosphorylation (Tsai et al. 2011), a decrease in ß1-intergin expression 272 and upregulation of caspase-3 (Sendzik et al. 2005), as well as changes in epigenetic metabolism 273 (Badal et al. 2015). Further studies have demonstrated increases in biomarkers of mitochondrial 274 oxidative stress, as well as deletion or double stranded breaks in $m t$ DNA preceding loss of 275 viability in a number of mammalian cell cultures as a result of FQ treatment (Badal et al. 2015;

276 Lawrence et al. 1996; Pouzaud et al. 2004). Moreover, studies show that decorin has the

277 potential to inhibit cell proliferation via TGF- $\beta$ (Ruoslahti \& Yamaguchi 1991; Ruoslahti et al. 
278 1992) and via the down-regulation of EGF receptors (Csordas et al. 2000). Considering our study

279 demonstrated decreased overall PG synthesis induced by CPX, we suggest that suboptimal

280 extracellular concentrations of decorin may be contributing to reduced tenocyte viability in our

281 study. However, the decrease in PG synthesis observed in the current study cannot be solely

282 attributed to one PG and further studies are needed to identify whether decorin metabolism is

283 specifically affected by CPX.

284

285 We also showed an inability of tenocyte viability in whole tissue explants to recover following 8

286 days cessation of CPX treatment. This finding suggests a potential contributing mechanism to the

287 latency between cessation of FQ therapy and development of tendon pathology reported in the

288 literature which can be as high as 6 months post-therapy. Studies have shown that tenocytes are

289 able to monitor and respond to changes in their mechanical environment (Arnoczky et al. 2004).

290 Consequently, we speculate that prolonged reductions in tenocyte viability would result in

291 diminished ability of tendons to appropriately monitor the extracellular environment and adapt to

292 load, which is shown to be a feature of early-stage tendinopathy (Cook et al. 2016; Maffulli et al. 293 2004).

294

295 Measuring ${ }^{[35]}$ S-incorporation into the tissue allows the study of sulphation of GAGs covalently 296 bound to the PG core protein (Beresford et al. 1987; Vogel \& Hernandez 1992). This approach 297 allowed us to measure the CPX-induced changes on PG synthesis. Our findings corroborate the 298 results of Williams et al (2000) which found that in fibroblasts derived from Achilles tendon and 299 paratenon, CPX $(5-50 \mu \mathrm{g} / \mathrm{mL})$ reduced PG synthesis in a dose dependent manner by up to $53 \%$ 300 (Williams et al. 2000). Similar findings were also reported in canine chondrocytes (Burkhardt et 
301 al. 1993) and chicken tendon-derived cells (Yoon et al. 2004a) treated with difloxacin and

302 enrofloxacin, respectively. Furthermore, enrofloxacin has demonstrated an ability to induce

303 changes in the number of $N$-linked oligosaccharides attached to the decorin core protein (Yoon et

304 al. 2004b). Our findings also support in vivo evidence that showed FQs significantly decreased

$305{ }^{[35]}$ S-labelled PG synthesis within 24hrs in mouse cartilage and Achilles tendon (Simonin et al.

306 2000). Thus, our results demonstrate that short-term exposure to CPX induces cellular changes

307 which lead a decrease in PG synthesis. No significant change in GAG

308

309 Our results also showed that ${ }^{[35]}$ S-labelled PG synthesis in tissue explants recovered 8 days

310 following discontinuation of CPX (concentrations $>100 \mu \mathrm{g} / \mathrm{mL}$, as well as $1 \mu \mathrm{g} / \mathrm{mL}$ ). Although

311 the mechanism underlying this recovery is yet unknown, it is unlikely to be due to a concurrent

312 rebound in tenocyte viability as this was not shown to occur in our study. We speculate that upon

313 removal of CPX, tenocytes may be compensating for the reduction in PG synthesis induced by

314 higher concentrations of CPX, even with reduced tenocyte viability. Indeed, we have previously

315 shown that PGs in tendon are able to be turned over rapidly (within days) when compared to

316 collagen (Samiric et al. 2004). This may also, in part, explain the marked increase in PG

317 synthesis during recovery in tissue explants initially treated with $10 \mu \mathrm{g} / \mathrm{mL}$. Interestingly, this

318 finding is in contradiction to a study using multiparametric MRI of healthy human Achilles

319 tendons which showed an $\sim 25 \%$ reduction in sodium signal (a means of detecting GAG content)

32010 days after treatment with CPX (Juras et al. 2015). However, these authors also reported that

321 the GAG-related sodium signal returned to baseline at a 5-month follow up, and that none of the

322 subjects involved developed any clinical symptoms of Achilles tendinopathy. This suggests that

323 in vivo recovery of PG metabolism after CPX treatment is slower than what we have observed in 
324 vitro. Whether delayed in vivo recovery of PG synthesis also contributes to the latency of 325 symptom onset clinically is yet to be established.

326

327 While we showed CPX down-regulated versican $m$ RNA, this is unlikely to explain the 328 demonstrated reduction in PG synthesis as this only occurred at the highest dosage. Additionally, 329 the down-regulation in $m$ RNA expression of biglycan, aggrecan and versican at various initial 330 CPX concentrations shown after 8 days discontinuation of treatment coincided with an observed 331 return to control level ${ }^{[35]} \mathrm{S}$-labelled PG synthesis. This suggest a mechanism outside $m$ RNA 332 expression changes and raises the possibility that the observed reduction in PG synthesis is 333 attributable to direct alteration of glycosylation and/or post-translational regulation of PGs rather 334 than their $m$ RNA expression. Indeed, it has been reported previously that total monosaccharide 335 content is reduced in equine tenocytes treated with enrofloxacin (Yoon et al. 2004a). However,

336 we were unable to support these findings in our current study as no significant changes in GAG 337 concentration were shown after the treatment period. The variability in these data make 338 speculation around the underlying mechanism of reduced PG synthesis difficult and warrants 339 further investigation.

341 Proper tenocyte and matrix metabolism are vital for tendon adaptation to load as well as healing 342 after injury or pathology. Thus, we propose that the observed effects in this study induce changes

343 that predispose a tendon to structrual pathology during or after load application, and any

344 subsequent development of structural pathology increases the risk of rupture. This may explain

345 why FQ-associated tendinopathy preferentially affects high load and weight bearing tendons,

346 particularly the Achilles tendon (Lewis \& Cook 2014). Under normal circumstances, high strain 
347 tendons undergo more rapid matrix turnover than low strain tendons in order to be able to rapidly

348 adapt to increased amounts of load (Bank et al. 1999). Affecting tendons that are already limited

349 in their capacity to heal would also explain the increased prevalence of FQ-associated

350 tendinopathy amongst the elderly and those concurrently using corticosteroids (Khaliq \& Zhanel $3512003)$.

352

353

354 Conclusions

355 In summary, our results demonstrate that both tenocyte viability and synthesis of PGs are 356 suppressed in explants of equine tendon following treatment with CPX. This corroborates

357 previously published literature which has found reduction of tenocyte viability and PG synthesis

358 in vitro in numerous species and confirms that these effects occur in a whole tissue explant

359 culture which more closely simulates the in vivo environment on tenocytes. These results suggest

360 that administration of fluoroquinolones such as CPX may alter the ability of tendons to undergo

361 normal adaptive turnover, even after discontinuation of FQ therapy. This study further

362 demonstrates that CPX-induced reduction in tenocyte viability does not recover within 8 days of

363 removal of CPX, and we suggest this may be a contributing mechanism to the delayed onset of

364 pathology reported clinically after FQ therapy.

365

366 We suggest future research aim to investigate the effects of fluoroquinolones on PG catabolism,

367 as well as characterization of the metabolism of individual PGs during and after FQ treatment.

368 This would provide a complete picture regarding the effects of FQs on PG metabolism in tendon.

369 And, future investigations should attempt to reproduce the observed effects by us and previous

370 investigators of FQs on tendon PG metabolism in a live animal model. 
372

373

374

375

376

377

378

379

380

381

382

383

384

385

386

387

388

389

390

391

392

393

394

395

396

397

398

399

400

401

402

403

404

405

406

407

408

409

410

411

412

413

414

\section{Acknowledgements}

No ethical approval was required for this study as animals were not euthanized for the purposes

of this study and all tissue was kindly provided by Tooradin Knackery, Tooradin, Victoria.

Ciprofloxacin lactate was kindly provided by Dr. John Daffy, Head of Infectious Diseases at St.

Vincent's Hospital, Melbourne, Australia.

\section{References}

Alves C, Mendes D, and Marques FB. 2019. Fluoroquinolones and the risk of tendon injury: a systematic review and meta-analysis. Eur J Clin Pharmacol 75:1431-1443. 10.1007/s00228-019-02713-1

Arnoczky SP, Tian T, Lavagnino M, and Gardner K. 2004. Ex vivo static tensile loading inhibits MMP-1 expression in rat tail tendon cells through a cytoskeletally based mechanotransduction mechanism. J Orthop Res 22:328-333. 10.1016/S07360266(03)00185-2

Badal S, Her YF, and Maher LJ, 3rd. 2015. Nonantibiotic Effects of Fluoroquinolones in Mammalian Cells. J Biol Chem 290:22287-22297. 10.1074/jbc.M115.671222

Bank RA, TeKoppele JM, Oostingh G, Hazleman BL, and Riley GP. 1999. Lysylhydroxylation and non-reducible crosslinking of human supraspinatus tendon collagen: changes with age and in chronic rotator cuff tendinitis. Ann Rheum Dis 58:35-41.

Bendele AM, Hulman JF, Harvey AK, Hrubey PS, and Chandrasekhar S. 1990. Passive role of articular chondrocytes in quinolone-induced arthropathy in guinea pigs. Toxicol Pathol 18:304-312. 10.1177/019262339001800209

Beresford JN, Fedarko NS, Fisher LW, Midura RJ, Yanagishita M, Termine JD, and Robey PG. 1987. Analysis of the proteoglycans synthesized by human bone cells in vitro. J Biol Chem 262:17164-17172.

Bernard-Beaubois K, Hecquet C, Hayem G, Rat P, and Adolphe M. 1998. In vitro study of cytotoxicity of quinolones on rabbit tenocytes. Cell Biol Toxicol 14:283-292.

Burkhardt JE, Hill MA, Carlton WW, and Kesterson JW. 1990. Histologic and histochemical changes in articular cartilages of immature beagle dogs dosed with difloxacin, a fluoroquinolone. Vet Pathol 27:162-170. 10.1177/030098589002700303

Burkhardt JE, Hill MA, Lamar CH, Smith GN, Jr., and Carlton WW. 1993. Effects of difloxacin on the metabolism of glycosaminoglycans and collagen in organ cultures of articular cartilage. Fundam Appl Toxicol 20:257-263.

Cook JL, Rio E, Purdam CR, and Docking SI. 2016. Revisiting the continuum model of tendon pathology: what is its merit in clinical practice and research? Br J Sports Med 50:11871191. 10.1136/bjsports-2015-095422

Corrao G, Zambon A, Bertu L, Mauri A, Paleari V, Rossi C, and Venegoni M. 2006. Evidence of tendinitis provoked by fluoroquinolone treatment: a case-control study. Drug Saf 29:889896. 10.2165/00002018-200629100-00006

Csordas G, Santra M, Reed CC, Eichstetter I, McQuillan DJ, Gross D, Nugent MA, Hajnoczky G, and lozzo RV. 2000. Sustained down-regulation of the epidermal growth factor 
415

416

417

418

419

420

421

422

423

424

425

426

427

428

429

430

431

432

433

434

435

436

437

438

439

440

441

442

443

444

445

446

447

448

449

450

451

452

453

454

455

456

457

458

459

460

461

462

463

464 receptor by decorin. A mechanism for controlling tumor growth in vivo. J Biol Chem 275:32879-32887. 10.1074/jbc.M005609200

Danielson KG, Baribault H, Holmes DF, Graham H, Kadler KE, and lozzo RV. 1997. Targeted disruption of decorin leads to abnormal collagen fibril morphology and skin fragility. $J$ Cell Biol 136:729-743.

Egerbacher M, Edinger J, and Tschulenk W. 2001. Effects of enrofloxacin and ciprofloxacin hydrochloride on canine and equine chondrocytes in culture. Am J Vet Res 62:704-708.

Farndale RW, Buttle DJ, and Barrett AJ. 1986. Improved quantitation and discrimination of sulphated glycosaminoglycans by use of dimethylmethylene blue. Biochim Biophys Acta 883:173-177.

Fernandez-Cuadros ME, Casique-Bocanegra LO, Albaladejo-Florin MJ, Gomez-Duenas S, Ramos-Gonzalez C, and Perez-Moro OS. 2019. Bilateral Levofloxacin-Induced Achilles Tendon Rupture: An Uncommon Case Report and Review of the Literature. Clin Med Insights Arthritis Musculoskelet Disord 12:1179544119835222. 10.1177/1179544119835222

Gillet P, Hestin D, Renoult E, Netter P, and Kessler M. 1995. Fluoroquinolone-induced tenosynovitis of the wrist mimicking de Quervain's disease. Br J Rheumatol 34:583-584.

Harrell RM. 1999. Fluoroquinolone-induced tendinopathy: What do we know? Southern Medical Journal 92:622-625.

Juras V, Winhofer Y, Szomolanyi P, Vosshenrich J, Hager B, Wolf P, Weber M, Luger A, and Trattnig S. 2015. Multiparametric MR Imaging Depicts Glycosaminoglycan Change in the Achilles Tendon during Ciprofloxacin Administration in Healthy Men: Initial Observation. Radiology 275:763-771. 10.1148/radiol.15140484

Khaliq Y, and Zhanel GG. 2003. Fluoroquinolone-associated tendinopathy: a critical review of the literature. Clin Infect Dis 36:1404-1410. 10.1086/375078

Lawrence JW, Claire DC, Weissig V, and Rowe TC. 1996. Delayed cytotoxicity and cleavage of mitochondrial DNA in ciprofloxacin-treated mammalian cells. Mol Pharmacol 50:11781188.

Lewis T, and Cook J. 2014. Fluoroquinolones and tendinopathy: a guide for athletes and sports clinicians and a systematic review of the literature. Journal of athletic training 49:422427.

Lim S, Hossain MA, Park J, Choi SH, and Kim G. 2008. The effects of enrofloxacin on canine tendon cells and chondrocytes proliferation in vitro. Vet Res Commun 32:243-253. 10.1007/s11259-007-9024-8

Lowes DA, Wallace C, Murphy MP, Webster NR, and Galley HF. 2009. The mitochondria targeted antioxidant MitoQ protects against fluoroquinolone-induced oxidative stress and mitochondrial membrane damage in human Achilles tendon cells. Free Radic Res 43:323-328. 10.1080/10715760902736275

Maffulli N, Sharma P, and Luscombe KL. 2004. Achilles tendinopathy: aetiology and management. J R Soc Med 97:472-476. 10.1258/jrsm.97.10.472

Pouzaud F, Bernard-Beaubois K, Thevenin M, Warnet JM, Hayem G, and Rat P. 2004. In vitro discrimination of fluoroquinolones toxicity on tendon cells: involvement of oxidative stress. J Pharmacol Exp Ther 308:394-402. 10.1124/jpet.103.057984

Ribard P, Audisio F, Kahn MF, De Bandt M, Jorgensen C, Hayem G, Meyer O, and Palazzo E. 1992. Seven Achilles tendinitis including 3 complicated by rupture during fluoroquinolone therapy. J Rheumatol 19:1479-1481.

Riley G. 2008. Tendinopathy--from basic science to treatment. Nat Clin Pract Rheumatol 4:8289. $10.1038 /$ ncprheum 0700

Ruoslahti E, and Yamaguchi Y. 1991. Proteoglycans as modulators of growth factor activities. Cell 64:867-869. 
465

466

467

468

469

470

471

472

473

474

475

476

477

478

479

480

481

482

483

484

485

486

487

488

489

490

491

492

493

494

495

496

497

498

499

500

501

502

503

504

Ruoslahti E, Yamaguchi Y, Hildebrand A, and Border WA. 1992. Extracellular matrix/growth factor interactions. Cold Spring Harb Symp Quant Biol 57:309-315.

Samiric T, Ilic MZ, and Handley CJ. 2004. Characterisation of proteoglycans and their catabolic products in tendon and explant cultures of tendon. Matrix Biol 23:127-140. 10.1016/j.matbio.2004.03.004

Sendzik J, Shakibaei M, Schafer-Korting M, and Stahlmann R. 2005. Fluoroquinolones cause changes in extracellular matrix, signalling proteins, metalloproteinases and caspase-3 in cultured human tendon cells. Toxicology 212:24-36. 10.1016/j.tox.2005.04.002

Simonin MA, Gegout-Pottie P, Minn A, Gillet P, Netter P, and Terlain B. 2000. Pefloxacininduced achilles tendon toxicity in rodents: biochemical changes in proteoglycan synthesis and oxidative damage to collagen. Antimicrob Agents Chemother 44:867-872.

Stahlmann R, Forster C, Shakibaei M, Vormann J, Gunther T, and Merker HJ. 1995. Magnesium deficiency induces joint cartilage lesions in juvenile rats which are identical to quinolone-induced arthropathy. Antimicrob Agents Chemother 39:2013-2018.

Tsai WC, Hsu CC, Chen CP, Chang HN, Wong AM, Lin MS, and Pang JH. 2011. Ciprofloxacin up-regulates tendon cells to express matrix metalloproteinase-2 with degradation of type I collagen. J Orthop Res 29:67-73. 10.1002/jor.21196

Vogel KG, and Hernandez DJ. 1992. The effects of transforming growth factor-beta and serum on proteoglycan synthesis by tendon fibrocartilage. Eur J Cell Biol 59:304-313.

Williams RJ, 3rd, Attia E, Wickiewicz TL, and Hannafin JA. 2000. The effect of ciprofloxacin on tendon, paratenon, and capsular fibroblast metabolism. Am J Sports Med 28:364-369. 10.1177/03635465000280031401

Wilton LV, Pearce GL, and Mann RD. 1996. A comparison of ciprofloxacin, norfloxacin, ofloxacin, azithromycin and cefixime examined by observational cohort studies. $\mathrm{Br} \mathrm{J}$ Clin Pharmacol 41:277-284.

Yoon JH, Brooks RL, Jr., Khan A, Pan H, Bryan J, Zhang J, Budsberg SC, Mueller PO, and Halper J. 2004a. The effect of enrofloxacin on cell proliferation and proteoglycans in horse tendon cells. Cell Biol Toxicol 20:41-54.

Yoon JH, Brooks RL, Jr., Zhao JZ, Isaacs D, and Halper J. 2004b. The effects of enrofloxacin on decorin and glycosaminoglycans in avian tendon cell cultures. Arch Toxicol 78:599608. 10.1007/s00204-004-0574-z

Yoshida K, Yabe K, Nishida S, Yamamoto N, Ohshima C, Sekiguchi M, Yamada K, and Furuhama K. 1998. Pharmacokinetic disposition and arthropathic potential of oral ofloxacin in dogs. J Vet Pharmacol Ther 21:128-132. 10.1046/j.1365-2885.1998.00114.x

Zhanel GG, and Noreddin AM. 2001. Pharmacokinetics and pharmacodynamics of the new fluoroquinolones: focus on respiratory infections. Curr Opin Pharmacol 1:459-463.

Zhanel GG, Walters M, Laing N, and Hoban DJ. 2001. In vitro pharmacodynamic modelling simulating free serum concentrations of fluoroquinolones against multidrug-resistant Streptococcus pneumoniae. J Antimicrob Chemother 47:435-440.

Peer) reviewing PDF | (2021:02:58014:1:0:NEW 20 Jun 2021) 
Figure 1

Cell viability, as determined by PrestoBlue ${ }^{\circledR}$ reagent assay, in equine derived tendon explant cultures after $96 \mathrm{hrs}$ treatment with 1, 10, $100 \& 300 \mu \mathrm{g} / \mathrm{mL} \mathrm{CPX}$

Values represent mean \pm SEM, expressed as $\%$ of control (CT). ${ }^{* *} p<0.01,{ }^{* * *} p<0.001$ compared with control. $n=4$

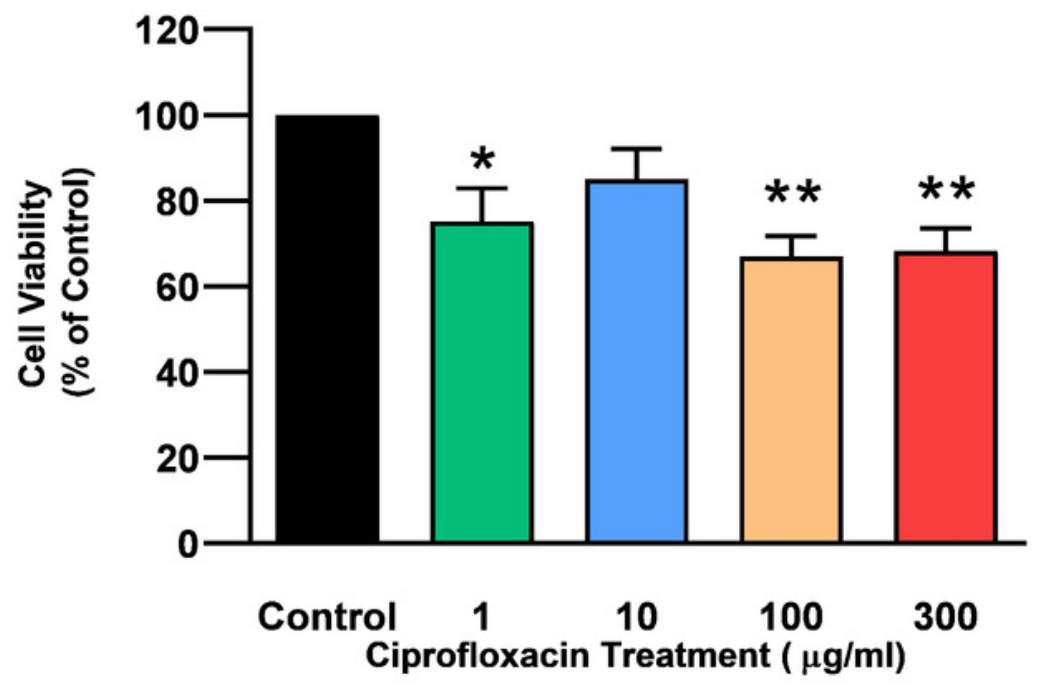




\section{Figure 2}

Cell viability, as determined by PrestoBlue ${ }^{\circledast}$ reagent assay, in equine derived tendon explant cultures after $96 \mathrm{hrs}$ treatment with 1, 10, $100 \& 300 \mu \mathrm{g} / \mathrm{mL} \mathrm{CPX}$ and subsequent 8-day recovery period

Values represent mean \pm SEM, expressed as $\%$ of control (CT). ${ }^{*} p<0.05,{ }^{* *} p<0.01$ compared with control. $n=7$

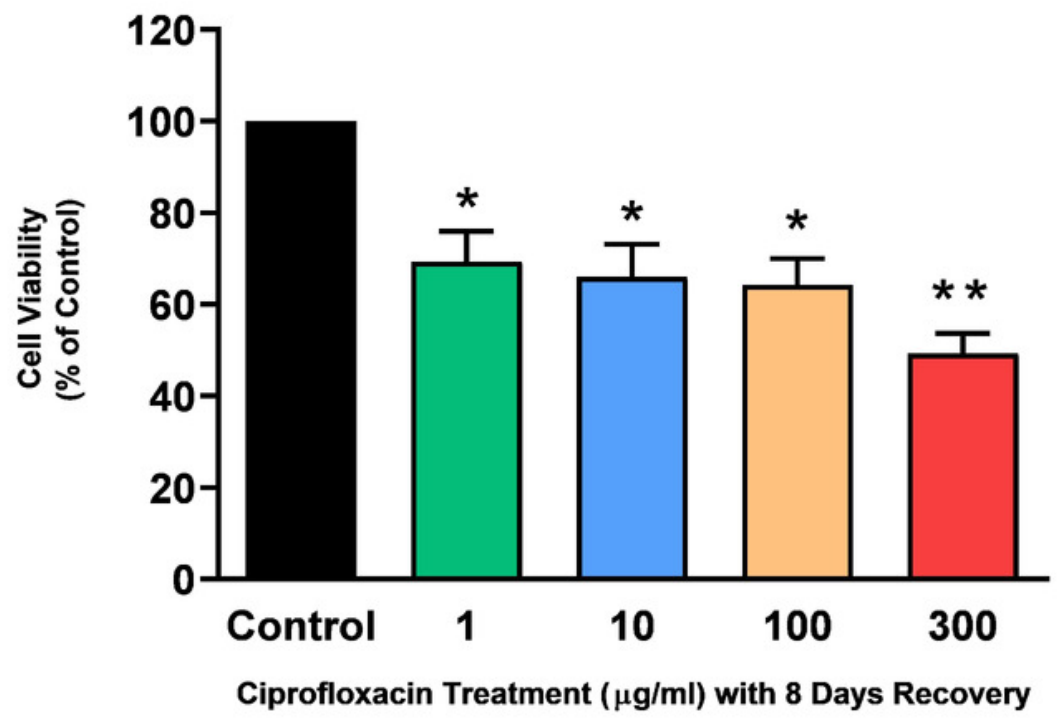


Figure 3

Chondroitin sulphate levels in equine derived tendon explants cultures after $96 \mathrm{hrs}$ treatment with $1,10,100$ or $300 \mu \mathrm{g} / \mathrm{mL}$ CPX

Values represent mean \pm SEM, expressed as $\%$ of control (CT). $n=3$

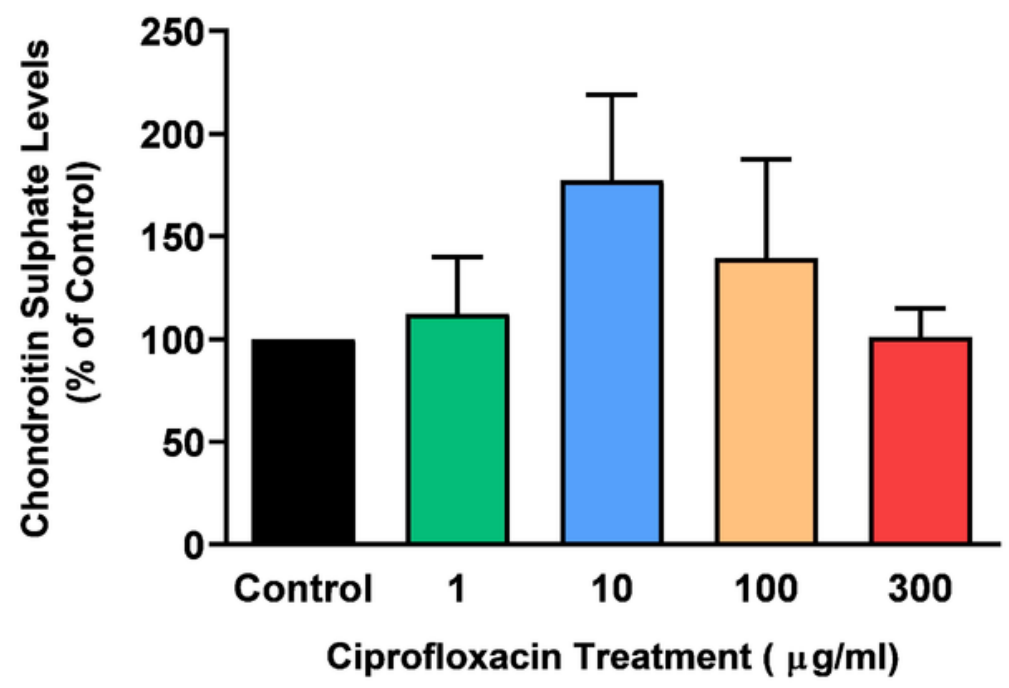


Figure 4

${ }^{35} \mathrm{~S}$-sulphate incorporation in equine derived tendon explants cultures after $96 \mathrm{hrs}$ treatment with $1,10,100$ or $300 \mu \mathrm{g} / \mathrm{mL} \mathrm{CPX}$

Values represent mean \pm SEM, expressed as $\%$ of control (CT). ${ }^{* *} p<0.01,{ }^{* * *} p<0.001$ compared with control. $n=6$

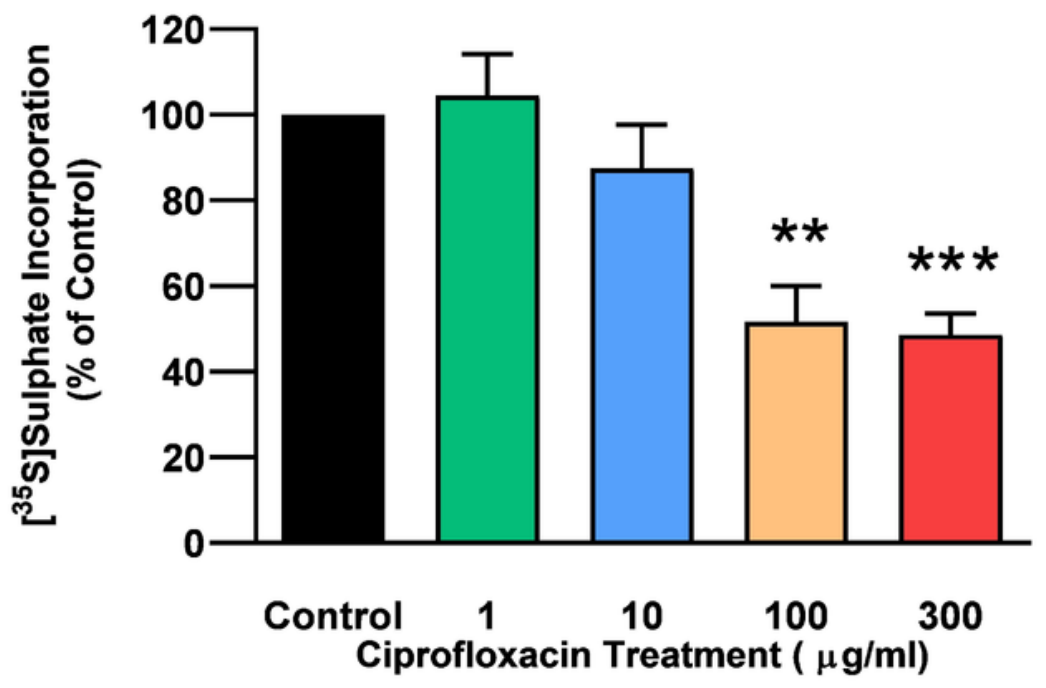


Figure 5

${ }^{35} \mathrm{~S}$-sulphate incorporation in equine derived tendon explants cultures after $96 \mathrm{hrs}$ treatment with $1,10,100$ or $300 \mu \mathrm{g} / \mathrm{mL} \mathrm{CPX}$ and subsequent 8-day recovery period

Values represent mean $\pm \mathrm{SEM}$, expressed as $\%$ of control (CT). ${ }^{*} p<0.05$ compared with control. $n=4$

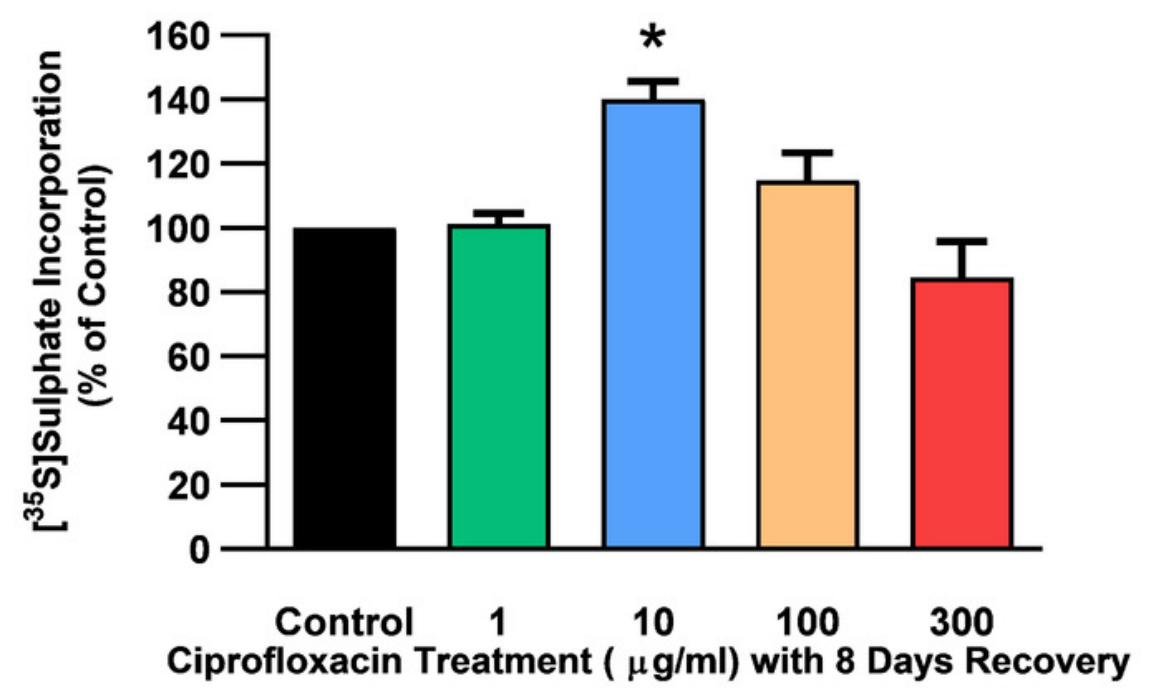


Figure 6

mRNA expression of decorin in equine derived tendon explant cultures after $96 \mathrm{hrs}$ treatment with $1,10,100 \& 300 \mu \mathrm{g} / \mathrm{mL} \mathrm{CPX}$

Results are expressed logarithmically. Values represent mean \pm SEM, expressed as fold change relative to control, normalised to GAPDH. $n=6$

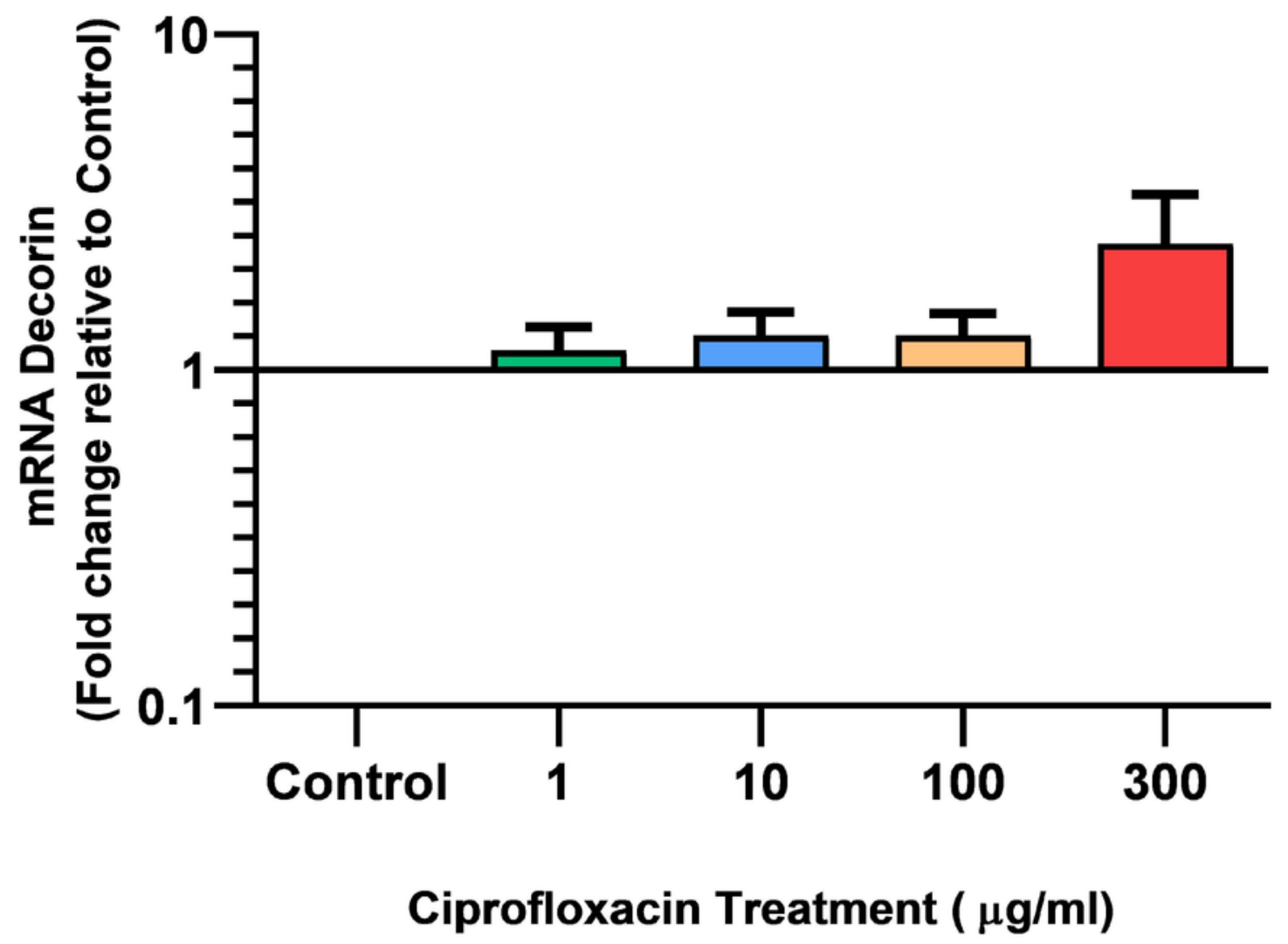


Figure 7

mRNA expression of fibromodulin in equine derived tendon explant cultures after $96 \mathrm{hrs}$ treatment with $1,10,100 \& 300 \mu \mathrm{g} / \mathrm{mL} \mathrm{CPX}$

Results are expressed logarithmically. Values represent mean \pm SEM, expressed as fold change relative to control, normalised to GAPDH. $n=6$

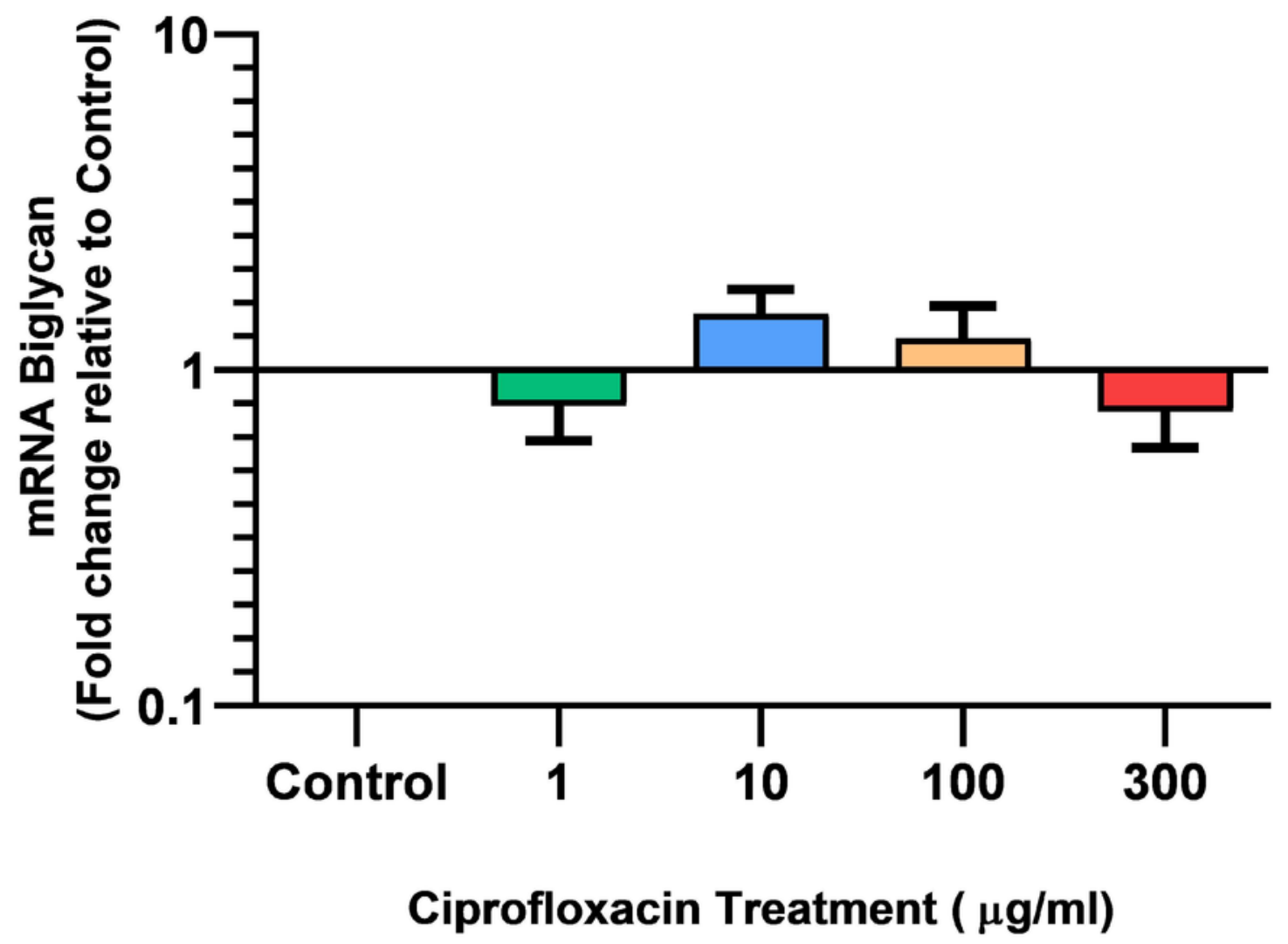


Figure 8

mRNA expression of biglycan in equine derived tendon explant cultures after $96 \mathrm{hrs}$ treatment with $1,10,100 \& 300 \mu \mathrm{g} / \mathrm{mL} \mathrm{CPX}$

Results are expressed logarithmically. Values represent mean \pm SEM, expressed as fold change relative to control, normalised to GAPDH. $n=6$

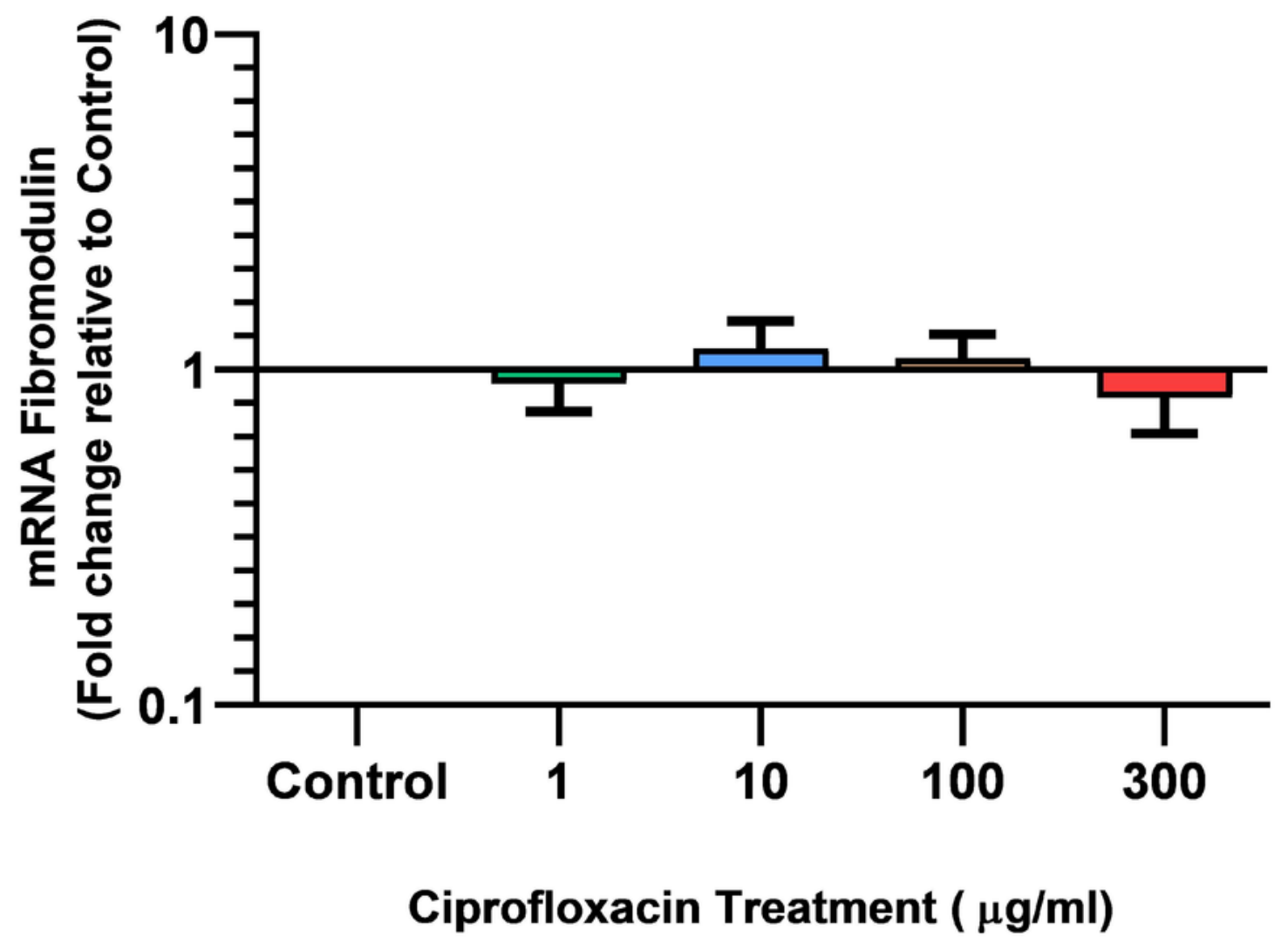


Figure 9

mRNA expression of aggrecan in equine derived tendon explant cultures after $96 \mathrm{hrs}$ treatment with $1,10,100 \& 300 \mu \mathrm{g} / \mathrm{mL} \mathrm{CPX}$

Results are expressed logarithmically. Values represent mean \pm SEM, expressed as fold change relative to control, normalised to GAPDH. $n=6$

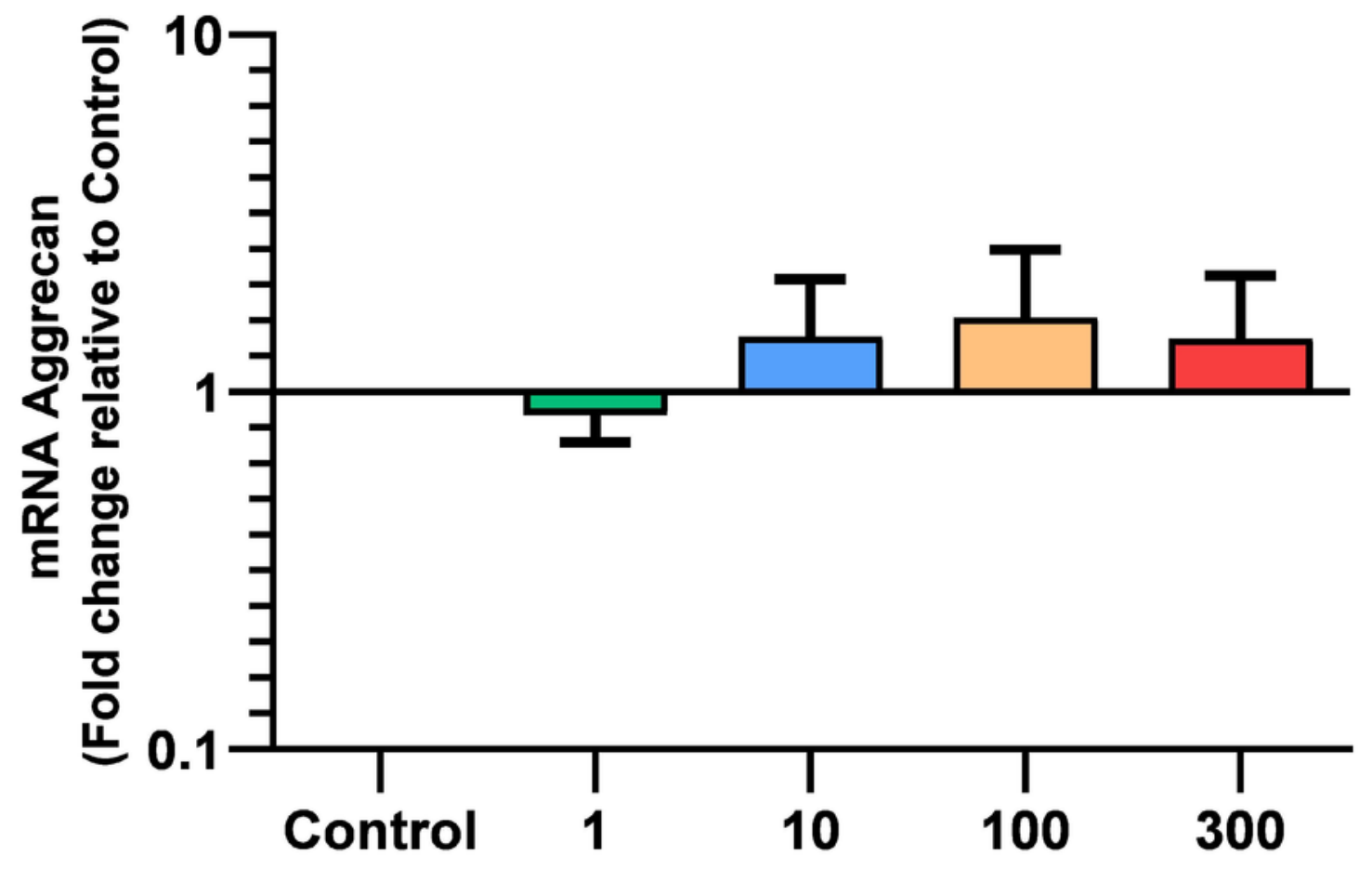

Ciprofloxacin Treatment $(\mu \mathrm{g} / \mathrm{ml})$ 
Figure 10

mRNA expression of versican in equine derived tendon explant cultures after $96 \mathrm{hrs}$ treatment with $1,10,100 \& 300 \mu \mathrm{g} / \mathrm{mL} \mathrm{CPX}$

Results are expressed logarithmically. Values represent mean \pm SEM, expressed as fold change relative to control, normalised to GAPDH. ${ }^{*} p<0.05$ compared with control. $n=6$

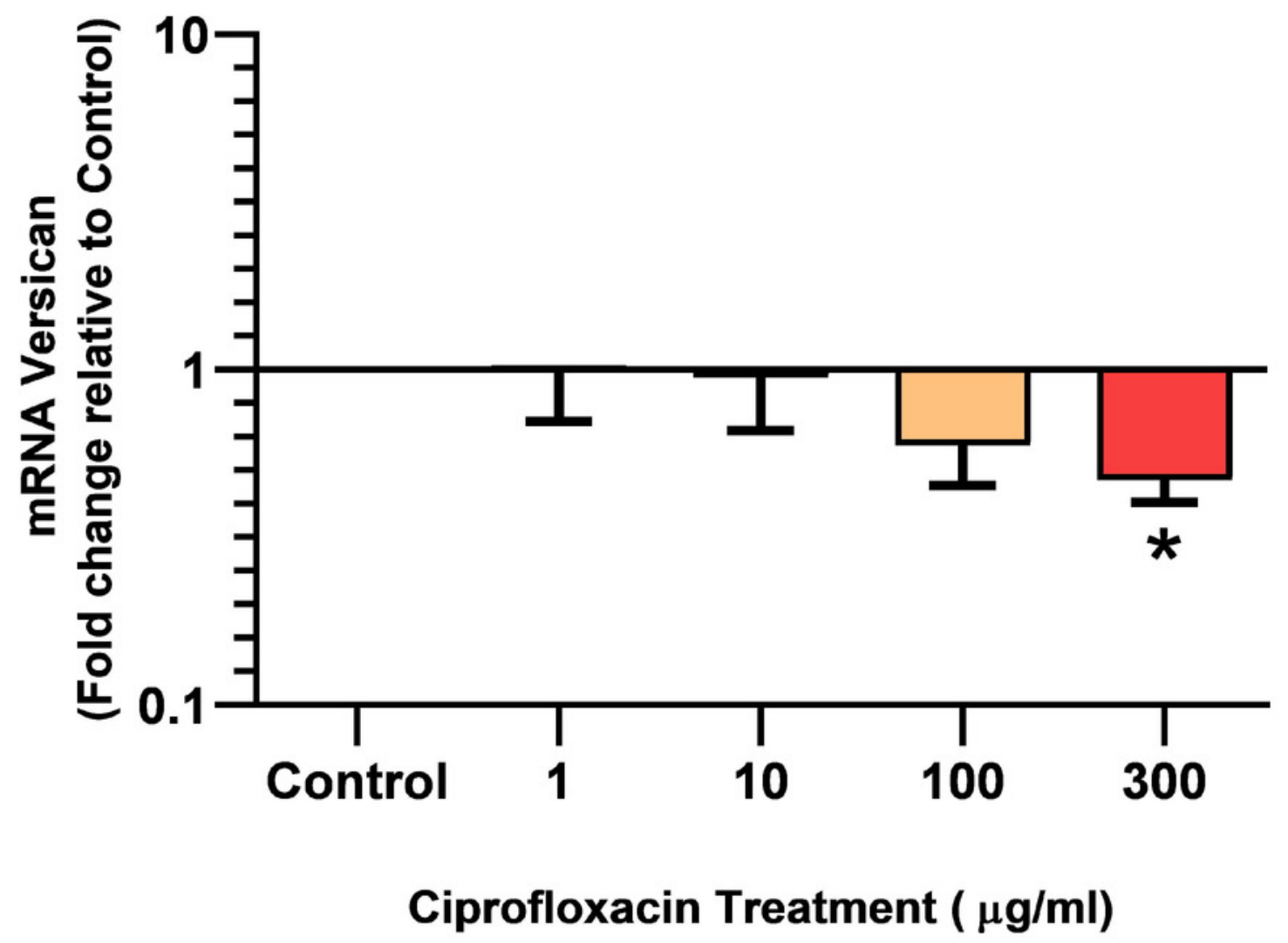


Figure 11

mRNA expression of decorin in equine derived tendon explant cultures after $96 \mathrm{hrs}$ treatment with $1,10,100 \& 300 \mu \mathrm{g} / \mathrm{mL} \mathrm{CPX}$ followed by 8 days in control conditions

Results are expressed logarithmically. Values represent mean \pm SEM, expressed as fold change relative to control, normalised to GAPDH. $n=4$

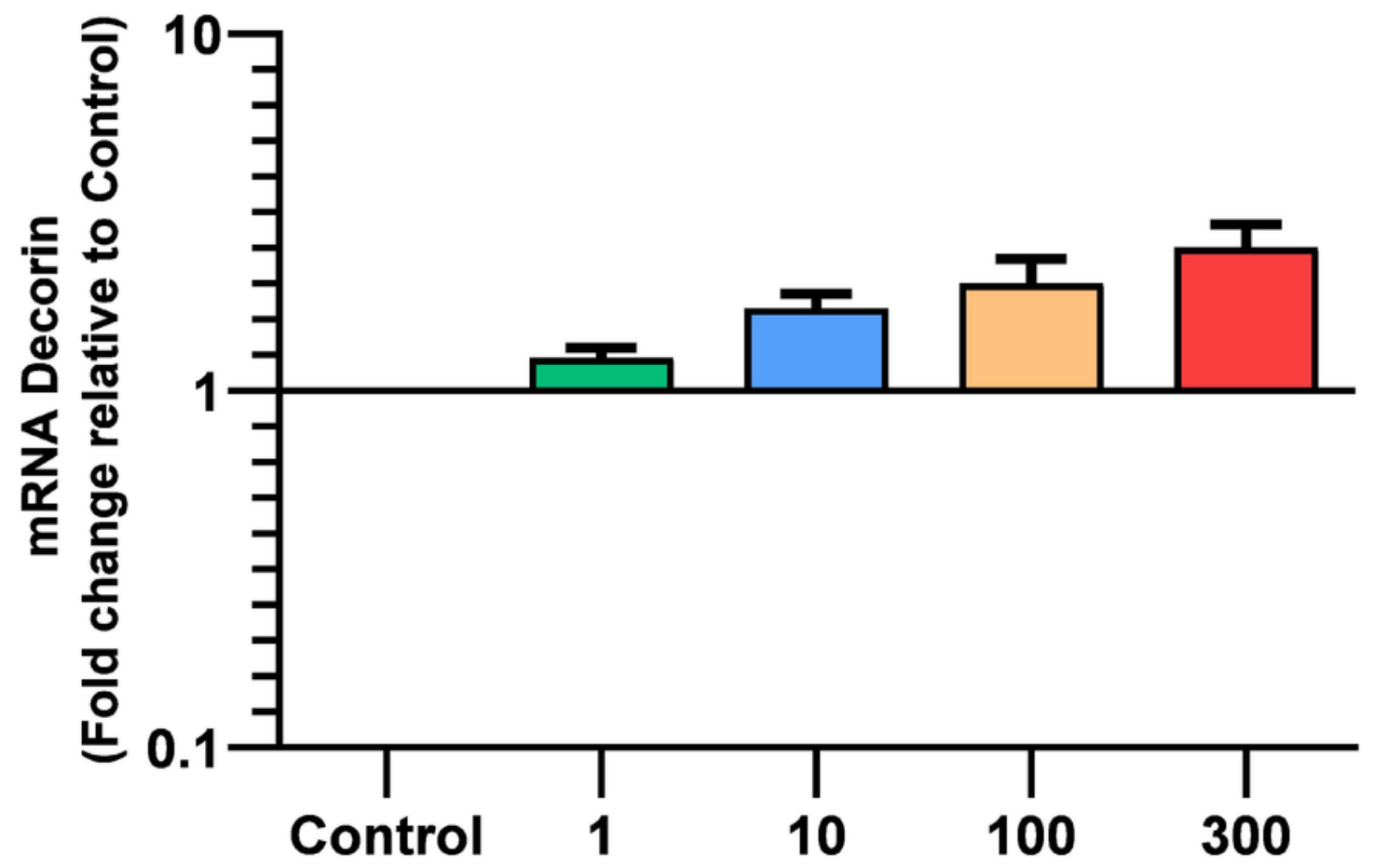

Ciprofloxacin Treatment ( $\mu \mathrm{g} / \mathrm{ml})$ with 8 Days Recovery 
Figure 12

mRNA expression of fibromodulin $m$ RNA expression in equine derived tendon explant cultures after 96 hrs treatment with 1, 10, $100 \& 300 \mu \mathrm{g} / \mathrm{mL}$ CPX followed by 8 days in control conditions

Results are expressed logarithmically. Values represent mean \pm SEM, expressed as fold change relative to control, normalised to GAPDH. $n=4$

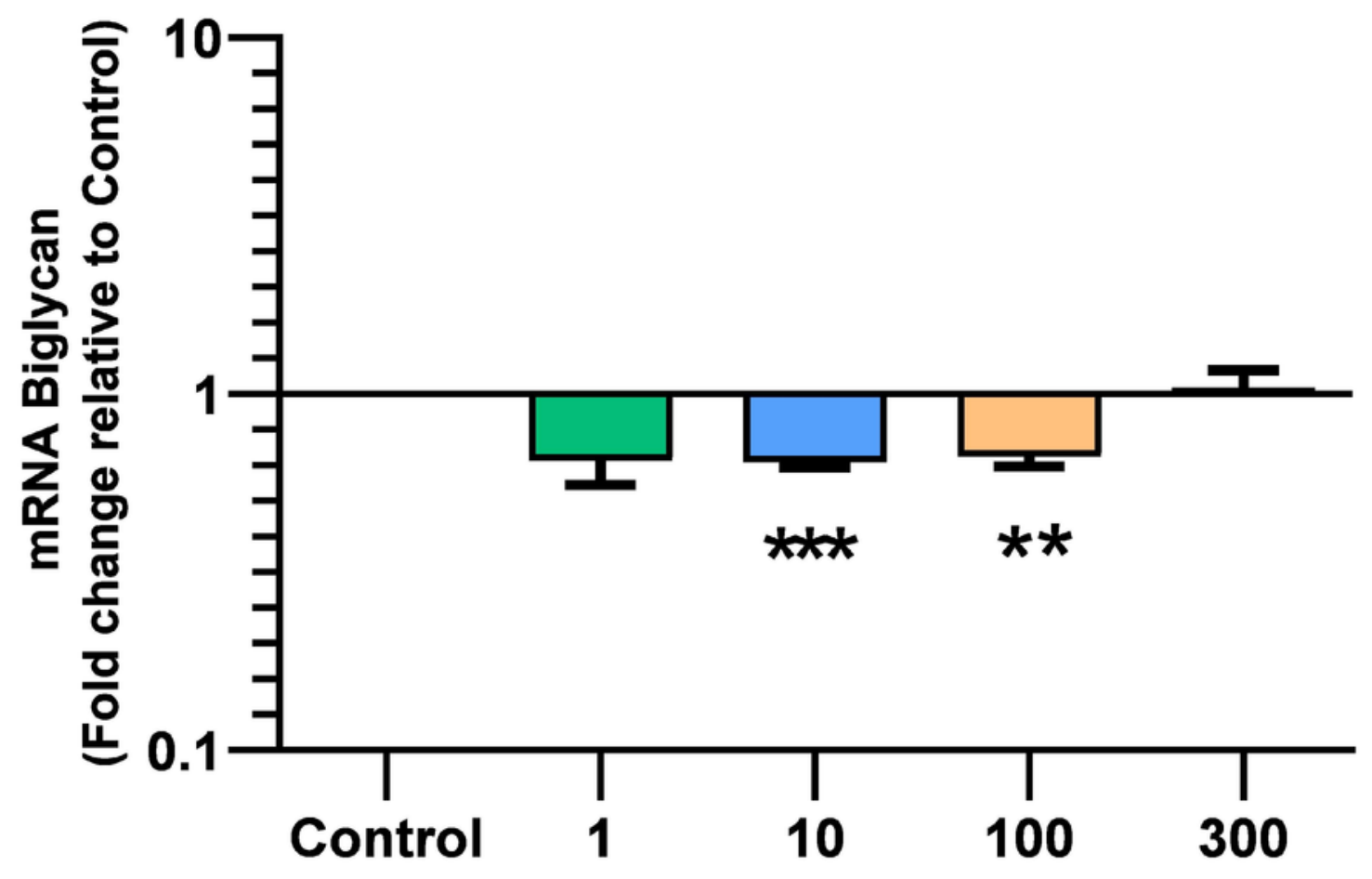

Ciprofloxacin Treatment ( $\mu \mathrm{g} / \mathrm{ml}$ ) with 8 Days Recovery 
Figure 13

mRNA expression of biglycan in equine derived tendon explant cultures after $96 \mathrm{hrs}$ treatment with $1,10,100 \& 300 \mu \mathrm{g} / \mathrm{mL} \mathrm{CPX}$ followed by 8 days in control conditions

Results are expressed logarithmically. Values represent mean $\pm S E M$, expressed as fold change relative to control, normalised to GAPDH. ${ }^{* *} p<0.01,{ }^{* * *} p<0.001$ compared with control. $n=4$

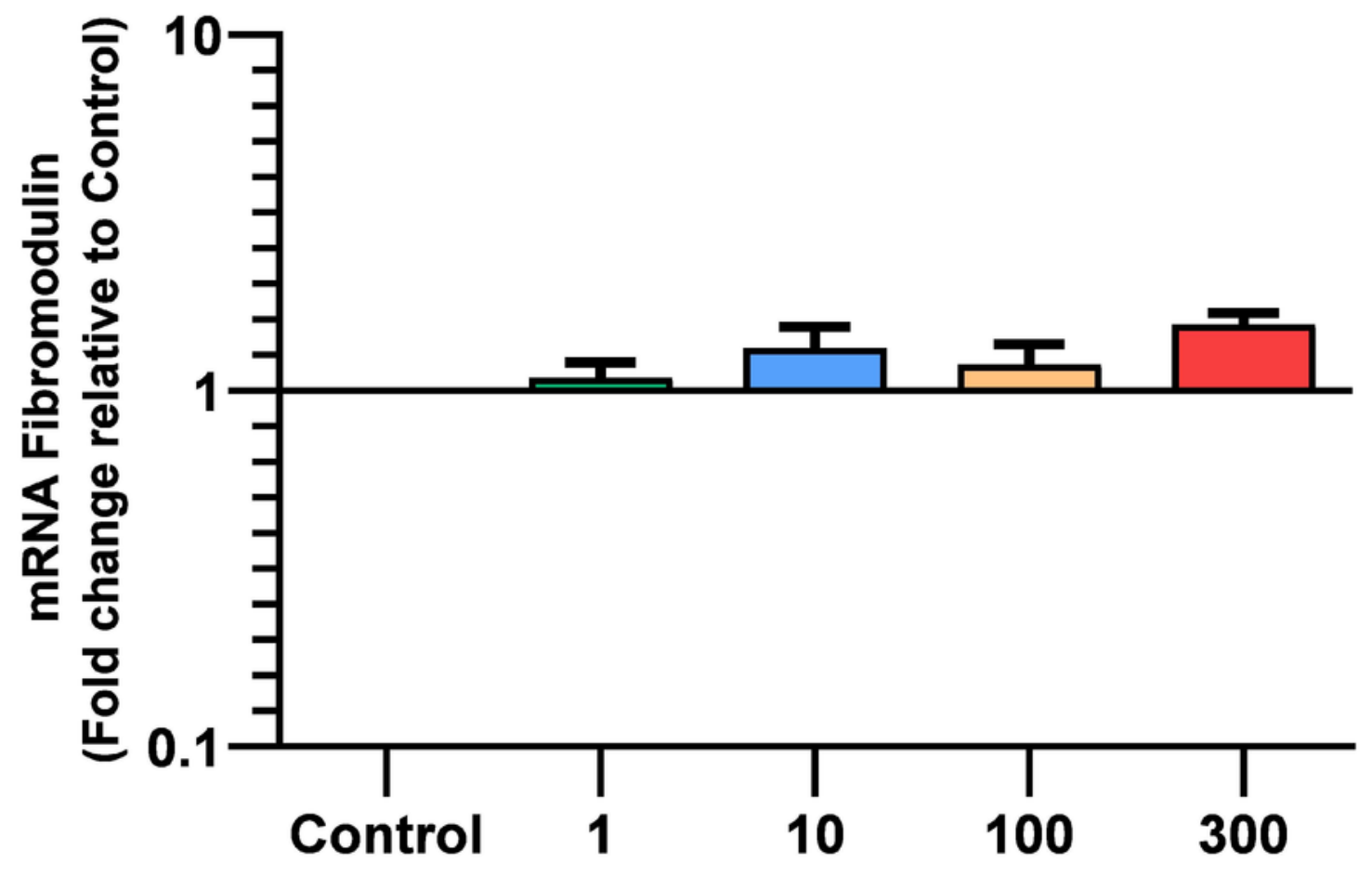

Ciprofloxacin Treatment ( $\mu \mathrm{g} / \mathrm{ml}$ ) with 8 Days Recovery 
Figure 14

mRNA expression of aggrecan in equine derived tendon explant cultures after $96 \mathrm{hrs}$ treatment with $1,10,100 \& 300 \mu \mathrm{g} / \mathrm{mL} \mathrm{CPX}$ followed by 8 days in control conditions

Results are expressed logarithmically. Values represent mean $\pm S E M$, expressed as fold change relative to control, normalised to GAPDH. ${ }^{*} p<0.05,{ }^{*} p<0.01$ compared with control. $n=4$

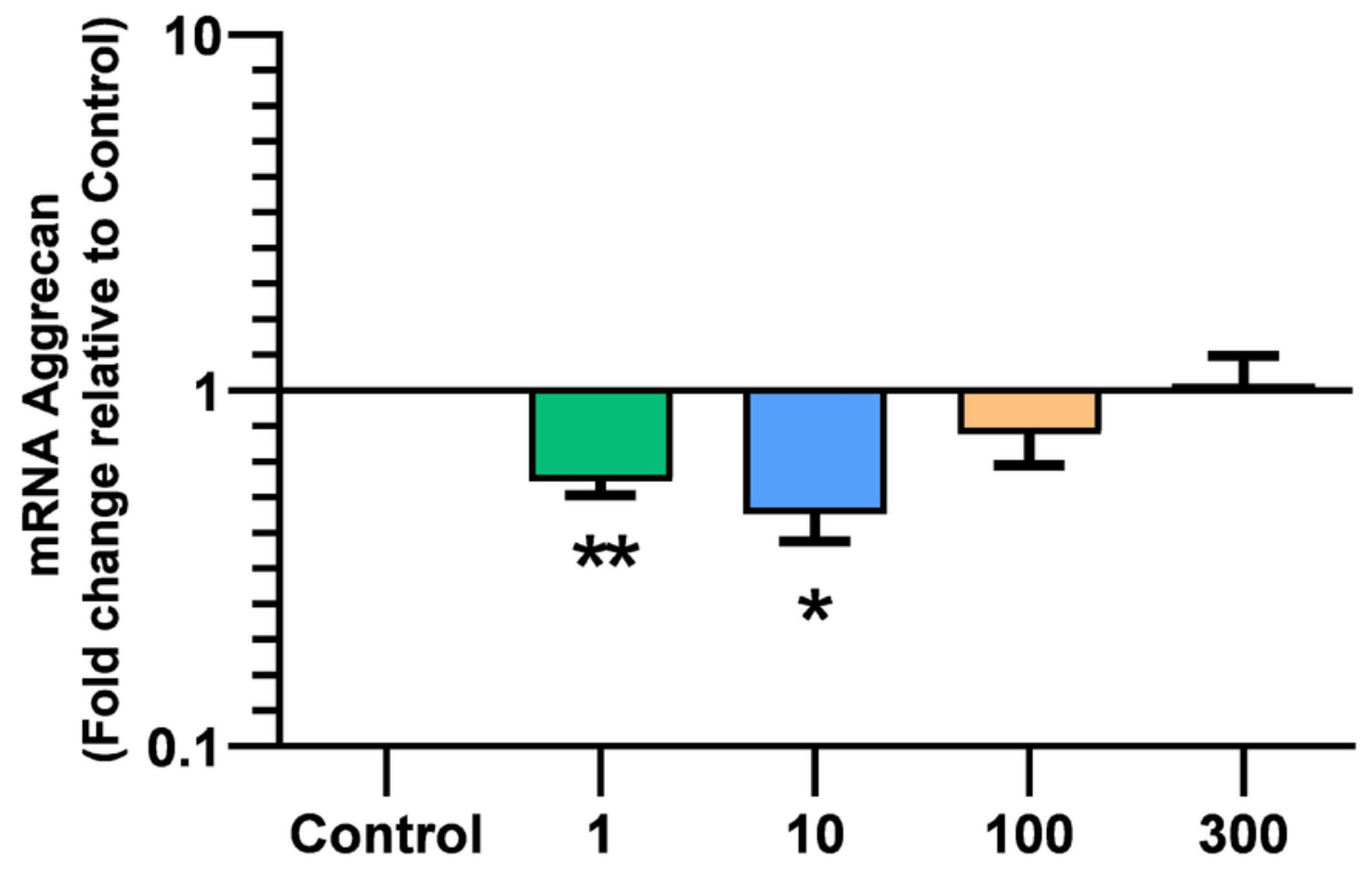

Ciprofloxacin Treatment ( $\mu \mathrm{g} / \mathrm{ml}$ ) with 8 Days Recovery 


\section{Figure 15}

mRNA expression of versican in equine derived tendon explant cultures after $96 \mathrm{hrs}$ treatment with $1,10,100 \& 300 \mu \mathrm{g} / \mathrm{mL} \mathrm{CPX}$ followed by 8 days in control conditions

Results are expressed logarithmically. Values represent mean $\pm S E M$, expressed as fold change relative to control, normalised to GAPDH. ${ }^{* *} p<0.01$ compared with control. $n=4$

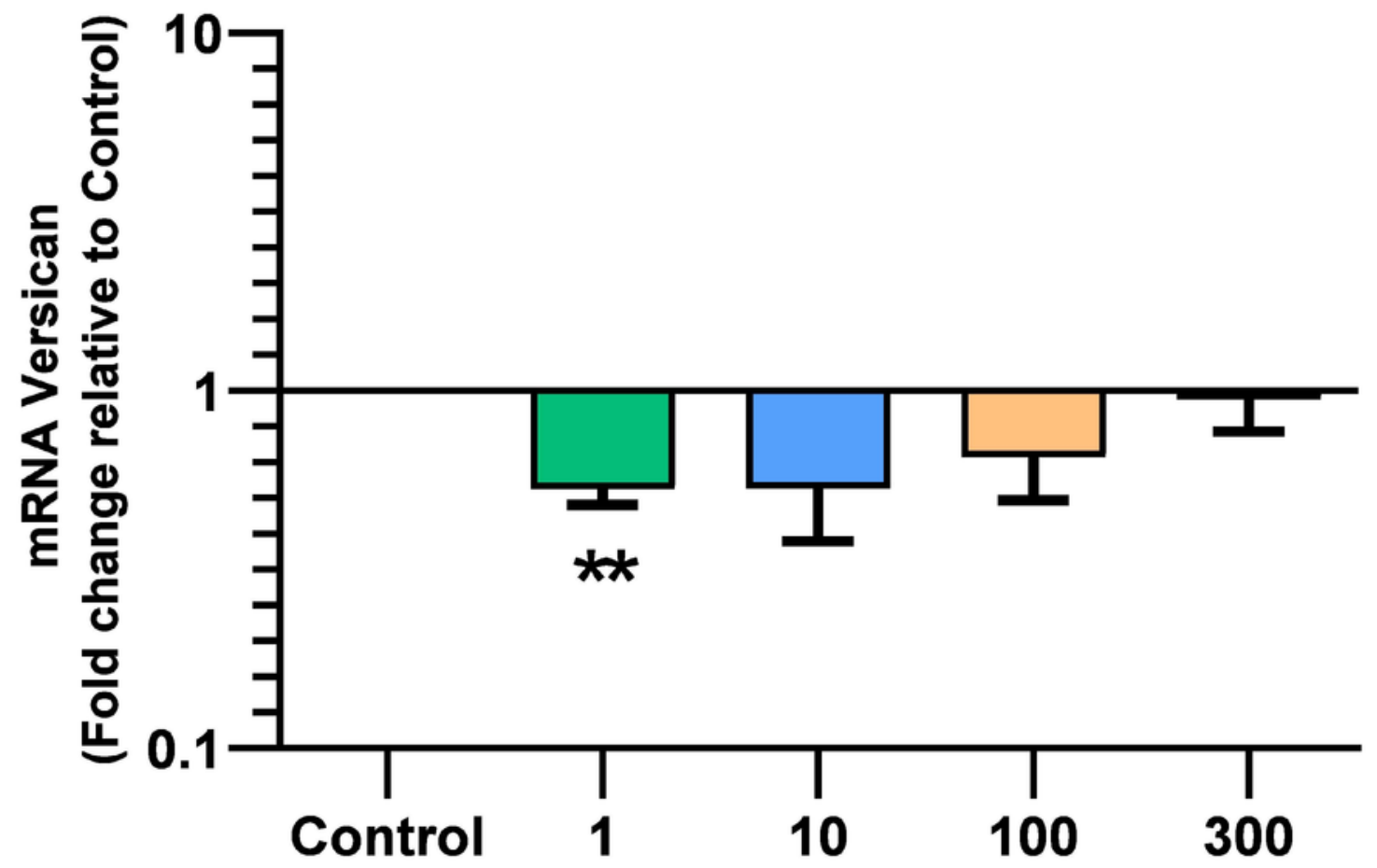

Ciprofloxacin Treatment ( $\mu \mathrm{g} / \mathrm{ml})$ with 8 Days Recovery 


\section{Table $\mathbf{1}$ (on next page)}

Oligonucleotide sequences for the specific equine primers used in RT-PCR. 


\section{Table 1.}

2 Oligonucleotide sequences for the specific equine primers used in RT-PCR.

\begin{tabular}{lllll}
\hline Gene & $\begin{array}{l}\text { Accession } \\
\text { Number }\end{array}$ & $\begin{array}{l}\text { Base } \\
\text { pair } \\
\text { length }\end{array}$ & Sense & Antisense \\
\hline GAPDH & DQ403057 & $138 \mathrm{bp}$ & GGCACCGTCAAGGCTGAGAAC & GGTGAAGACGCCAGTGGACTC \\
Aggrecan & NM_001135 & $127 \mathrm{bp}$ & TGCGTGGGTGACAAGGACAG & CAAGGCGTGTGGCGAAGAAC \\
Versican & NM_004385 & $147 \mathrm{bp}$ & ATCTGGATGGTGATGTGTTC & AATCGCAACTGGTCAAAGC \\
Decorin & BC005322 & $143 \mathrm{bp}$ & CTGGGCTGGACCGTTTCAAC & GATGGCATTGACAGCGGAAGG \\
Biglycan & BC002416 & $139 \mathrm{bp}$ & ACACCATCAACCGCCAGAGTC & GACAGCCACCGACCTCAGAAG \\
Fibromodulin & BC035281 & $145 \mathrm{bp}$ & GGCTGCTCTGGATTGCTCTC & CGGGTCAGGTTGTTGTGGTC \\
\hline
\end{tabular}

